\title{
Multiple pregnancies and its relationship with the development of retinopathy of prematurity (ROP)
}

This article was published in the following Dove Press journal:

Clinical Ophthalmology

19 December 2011

Number of times this article has been viewed

\author{
Mário Martins dos Santos \\ Mottal \\ João Borges Fortes Filho \\ Jacqueline Coblentz' \\ Claudia Amaral Fiorot ${ }^{3}$ \\ 'Department of Ophthalmology, \\ Faculty of Medicine, Federal \\ University of Rio de Janeiro, Rio de \\ Janeiro RJ, Brazil; ${ }^{2}$ Department of \\ Ophthalmology, Faculty of Medicine, \\ Federal University of Rio Grande \\ do Sul and Hospital de Clínicas de \\ Porto Alegre, Porto Alegre RS, Brazil; \\ ${ }^{3}$ Hospital Naval Marcílio Dias, Rio de \\ Janeiro RJ, Brazil
}

Background: The influence of multiple gestation on the occurrence of retinopathy of prematurity (ROP) is still not completely understood.

Objectives: To verify the incidence of any stage of ROP and threshold ROP in singletons and in multiple gestation among preterm infants.

Methods: This was an institutional, prospective, and descriptive cohort study, which included preterm newborns with birth weight (BW) of $1500 \mathrm{~g}$ or less and/or gestational age (GA) of 32 weeks or less, as admitted to the neonatal units at Laranjeiras and Amparo Hospitals in Rio de Janeiro, Brazil, between January 2001 and July 2005, and whom remained hospitalized for at least 28 days. There were no exclusion criteria. Patients were divided into two groups: Group 1 included multiples; and Group 2 consisted of singletons.

Results: A total of 159 infants that remained in neonatal unit care for at least 28 days were included in this study. Group 1 comprised 56 (35\%) multiples; and Group 2 comprised 103 (65\%) singletons. Mean BW was $1072 \mathrm{~g} \pm 272$ and $1089 \mathrm{~g} \pm 282$ in Groups 1 and 2, respectively (analysis of variance [ANOVA] $P>0.05$ ). Mean GA among multiple gestation (Group 1) was 29 weeks \pm 2.1 ; and 29 weeks \pm 2.4 among singletons (Group 2) (ANOVA $P>0.05$ ). Days in oxygen therapy ranged from 0 to 188 days. Median among Group 1 was 15 days, while median in Group 2 was 10 days (Kruskal-Wallis $P>0.05)$. Any stage ROP was detected in $66(41.5 \%)$ of the whole cohort comprising 159 babies. Among the 56 multiples, 30 (53.6\%) achieved any stage ROP, and among 103 singletons, 36 (35\%) achieved any stage ROP (Chi-square test $P<0.05)$. Threshold ROP occurred in $12(7.5 \%)$ of the 159 patients included. Three $(5.3 \%)$ patients from Group 1 and nine $(8.7 \%)$ patients in Group 2 reached threshold ROP needing laser treatment (Fisher's exact test $P>0.05$ ).

Conclusion: This study showed higher frequency of any stage of ROP in twins and triplets but not regarding threshold disease. Because of the relatively small number of patients in this sample, other studies are necessary to determine if gemelarity plays a role in the occurrence of ROP.

Keywords: prematurity, retinopathy of prematurity, gemelarity, prevalence

\section{Introduction}

Retinopathy of prematurity (ROP) is a multifactorial disease caused by numerous and complex vascular disturbances that occur at the immature retina of preterm neonates. ${ }^{1}$ ROP affects peripheral retinal vessels under formation; therefore, it does not occur after complete vascularization of the peripheral retina.,3 Etiology of ROP is not completely understood, but several factors related to prematurity seems to be connected to the disease. ${ }^{4}$ Low birth weight (BW), low gestational age (GA), and use of oxygen therapy in mechanical ventilation are considered the main risk factors for ROP.,
Correspondence: João Borges Fortes Filho

Hospital de Clínicas de

Porto Alegre, Rua Ramiro Barcelos, 2350, Porto Alegre RS, 90035-903, Brazil

Tel +5I 32229292

Email jbfortes@prorop.com.br 
Children born from multiple pregnancies present a higher risk of preterm delivery (GA $<37$ weeks after conception). Around 53\% of twins and $92 \%$ of triplets present low BW. Prematurity occurs in $47 \%$ of twins and in $91.6 \%$ of triplets. ${ }^{7}$

Although twins and triplets do not seem to have a higher risk of neonatal disturbances when compared to newborns with similar GA and BW from single gestations, there are some reports showing a higher incidence of ROP in infants from multiple pregnancies. ${ }^{6}$ The influence of multiple pregnancies regarding ROP occurrence is still not completely clear. ${ }^{8-11}$

The objective of this study is to verify the incidence of any stage of ROP and threshold ROP in singletons and in multiple-pregnancy newborns, as studied in two different neonatal intensive care units (NICUs) in Rio de Janeiro, Brazil.

\section{Methods}

\section{Study design and population}

This was an institutional, prospective, and descriptive cohort study, which included preterm newborns with BW of $1500 \mathrm{~g}$ or less and/or GA of 32 weeks or less at birth admitted to the neonatal units at Laranjeiras and Amparo Hospitals in Rio de Janeiro, Brazil, between January 2001 and July 2005, and whom remained hospitalized for at least 28 days. There were no exclusion criteria. Patients were divided into two groups: Group 1 included babies born form multiple gestation; and Group 2 consisted of singletons. Multiples were defined as children born from pregnancies with two or more fetuses simultaneously. ${ }^{12}$

\section{Ophthalmologic examination}

All patients were evaluated by two of the authors (Motta, Fiorot), both professionals with training for performing ROP screening and ROP treatment. Examination consisted of binocular indirect ophthalmoscopy after pupillary dilation with phenylephrine $2.5 \%$ and tropicamide $1 \%$. Eye drops were administered with 5-minute intervals, starting 40-60 minutes before examinations. Ophthalmologic examinations started between the fourth and sixth weeks of life, and assessments were repeated weekly if any stage of ROP was detected, or every 2 weeks until discharge if no ROP had occurred, as according to the Brazilian guidelines on the detection and treatment of ROP. ${ }^{13}$ Patients with threshold ROP were treated with transpupillary diode laser photocoagulation or by cryotherapy ablation. ${ }^{2,14,15}$

Primary clinical outcomes were ROP onset at any evolutionary stage and onset of severe ROP requiring treatment in Groups 1 and 2. Stages of ROP were recorded according to the $1984 / 1987$ International Classification, ${ }^{16}$ and corresponded to the most severe degree of ROP found in either eye during the examination period. Threshold disease was defined according to cryotherapy for retinopathy of prematurity (Cryo-ROP) study. ${ }^{14}$ ROP incidence was calculated for both groups.

Variables used to analyze risk factors for ROP were BW; GA (assessed by clinical history, early obstetric ecography, or neonatologist evaluation with Ballard or Capurro methods); gender; type of pregnancy (single or multiple); and duration of oxygen therapy.

\section{Statistical analysis}

To analyze the results on the continuous variables with normal variances, analysis of variance (ANOVA) tests were used, and for those variables with asymmetrical distribution, the Kruskal-Wallis test was employed. To analyze the categorical variables, the Chi-square and Fisher's exact tests were used. Results were considered significant for $P<0.05$.

\section{Results}

A total of 159 infants remained hospitalized for at least 28 days and were included in this study. Group 1 comprised 56 (35\%) born from multiple pregnancies; and Group 2 comprised 103 (65\%) singletons. Birth weight ranged between 500-1500 g including all patients. Mean BW was $1072 \mathrm{~g} \pm 272$ and $1089 \mathrm{~g} \pm 282$ in Groups 1 and 2, respectively (ANOVA $P>0.05$ ).

Gestational age ranged between 24-35 weeks at birth including all patients. Mean GA among multiple gestation (Group 1) was 29 weeks \pm 2.1 ; and 29 weeks \pm 2.4 among singletons (ANOVA $P>0.05$ ).

Days in oxygen therapy ranged from 0 to 188 days. Median among Group 1 was 15 days while median in Group 2 was 10 days (Kruskal-Wallis $P>0.05$ ).

Any stage of ROP was detected in 66 (41.5\%) of the whole cohort comprising 159 babies. Among the 56 multiplepregnancy patients, 30 (53.6\%) achieved any stage of ROP; and among 103 singleton babies, 36 (35\%) of them achieved any stage of ROP (Chi-square test $P<0.05$, Figure 1).

Threshold ROP occurred in 12 patients $(7.5 \%)$ of the 159 patients included. Three patients (5.3\%) from Group 1 and nine patients $(8.7 \%)$ in Group 2 reached threshold ROP needing diode laser treatment (Fisher's exact test $P>0.05$, Figure 2).

All but one of the 12 treated patients had complete regression of ROP after treatment. This Group 2 preterm, with 


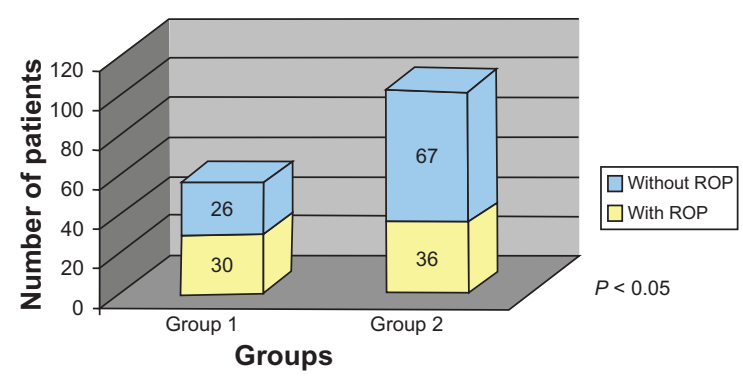

Figure I Retinopathy of prematurity (ROP) in multiples vs singles.

unfavorable outcome, underwent laser therapy but progressed to stage $4 \mathrm{~B}$ of ROP despite scleral buckling procedure in his right eye, and progressed to stage 5 of ROP in his left eye, despite pars plicata vitrectomy.

\section{Discussion}

There were $35 \%$ of multiple-gestation patients among the prospectively studied cohort of patients. Both Laranjeiras and Amparo neonatal units are reference centers for assisted pregnancies, which may explain the higher incidence of multiples in this study when compared to other authors. ${ }^{17}$ According to Barr et al, there are around $10 \%$ of prematurity among singletons. Among twins and triplets, $47 \%$ and $90 \%$, respectively, born prematurely and with low $\mathrm{BW}{ }^{7}$

In Group 1, 30 patients (53.6\%) achieved any stage of ROP and, in Group 2, 36 patients (35\%) achieved any stage of ROP (Chi-square test $P<0.05$ ). Threshold ROP occurred in three (5.3\%) patients in Group 1, and in nine (8.7\%), patients in Group 2 (Chi-square test $P>0.05$ ). Both groups were similar regarding GA, BW, and duration of oxygen therapy. Days in oxygen therapy ranged from 0 to 188 days. Median among Group 1 was 15 days while median in Group 2 was 10 days (Kruskal-Wallis $P>0.05$ ). This study did not find reference to all of these parameters simultaneously when groups were compared, which could explain the difference in the findings. Current knowledge about how to avoid fluctuation in the oxygen levels delivered to the preterm during the period under oxygen therapy (by monitoring $\mathrm{PaO}_{2}$ by pulse oximetry) has

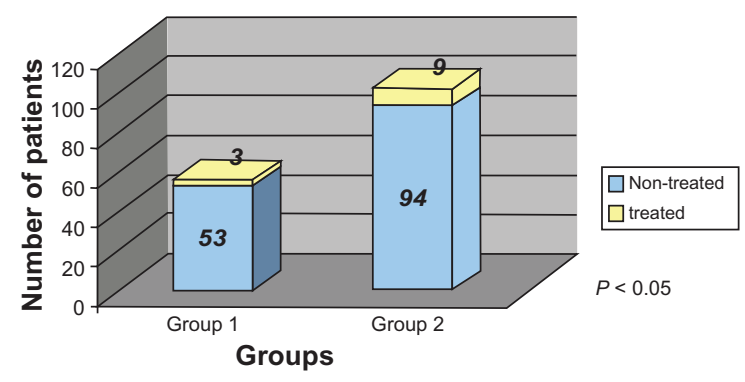

Figure 2 Threshold retinopathy of prematurity (ROP). led to a reduced occurrence of severe ROP among very low BW preterm infants. ${ }^{18}$ The guidelines issued by the American Academy of Pediatrics presently recommend maintaining $\mathrm{PaO}_{2}$ at $45-80 \mathrm{mmHg}$ with oxygen saturation limits of $85 \%$ for preterm infants with GA $>32$ weeks, and $85 \%-93 \%$ for newborn infants with GA $<32$ weeks. ${ }^{19}$

There are other suggested risk factors for ROP, such as hyperoxia; hypoxia; use of indomethacin, surfactants, and erythropoietin; occurrence of sepsis or intraventricular hemorrhage; and postnatal low weight gain, but with inconclusive results. ${ }^{20}$ This study did not include these factors within its parameters.

Recently, multiple pregnancies have been studied as a risk factor for ROP. ${ }^{8,921,22}$ Incidence of multiples increased $400 \%$ in the last 20 years, especially in triplets, ${ }^{7}$ possibly because of a higher incidence of pregnancy in older women, as well as a larger number of assisted pregnancies or fertilizations. ${ }^{8,10,11,22}$

Improvements in perinatal and neonatal intensive care has reduced the mortality rate of extremely low-BW infants. ${ }^{23}$ Multiple pregnancies usually present babies with low GA and $\mathrm{BW}$, both considered the main risk factor to develop ROP. ${ }^{7}$ Incidences of ROP are increasing in many countries, ${ }^{2}$ including Brazil, but this study could not find any reports on this issue in the Brazilian scientific literature.

With regard to threshold ROP, recent articles show inconclusive results comparing preterm babies born from single and multiple pregnancies. McKibbin et al related a higher incidence of threshold ROP among multiples born from assisted pregnancies. ${ }^{22}$ On the other hand, Blumenfeld et al found similar occurrence of stages 1, 2, and 3 ROP (prethreshold or threshold) when analyzing 149 premature infants from multiple gestations compared to 691 singletons. ${ }^{9}$ Watts and Adams related that in vitro fertilization could be a risk factor for threshold ROP after studying 179 preterm children born from different assisted conceptional methods, but the authors did not mention multiple pregnancies. ${ }^{11}$ The current study did not find statistical significance regarding the need for treatment between Groups 1 and 2, as in agreement with Blumenfeld et al, ${ }^{9}$ but the small number of threshold ROP patients in Group 1 may have influenced this result.

Twelve patients in the entire cohort were treated for threshold ROP in this study. Eleven of them were treated with transpupillary diode laser, and ten (90.9\%) presented regression of threshold ROP. Only one child had an unfavorable outcome. This infant, belonging to Group 2, underwent diode laser therapy but progressed to stage $4 \mathrm{~B}$ of ROP despite scleral buckling procedure in his right eye, and progressed to 
stage 5 of ROP in his left eye despite pars plicata vitrectomy. Only one child was treated with cryotherapy with good outcomes. These results are similar to those described by other authors. ${ }^{6,9,14}$

Of the 159 patients considered in this study, 66 (41.5\%) had any stage ROP. The results of this study support current literature. ${ }^{2,4,26}$ Although comparison with historic control groups allows patient selection, and thus ensure inclusion criteria are homogenous, it does not recognize that other factors, such as new drugs, advanced technologies, changes in NICU routines, or changes in population characteristics (like an increase of gemelarity), could affect the results.

McKibbin et al performed screening examination to evaluate ROP in $20 \%$ of children born after assisted conception. ${ }^{22}$ Twenty-three percent of the subjects presented with some stage of ROP, with a high incidence of patients requiring treatment. McKibbin et al did not mention the proportion of twin births in the population studied.2

Friling et al found in 99 newborns from multiples gestation and BW of $1500 \mathrm{~g}$ or less, a higher risk of developing ROP in the second twin, but logistic regression analysis showed that the smaller BW of the second twin, and not the order of deliverance, was the most important factor to ROP. ${ }^{8}$

Blumenfeld et al compared 149 infants born from multiple pregnancies to 691 from single pregnancies, and found ROP in 69 (46\%) of twins and 312 (45\%) of singletons, with no statistical difference in the incidence of the disease between the groups. ${ }^{9}$

Tomazzoli et al studied ROP in 77 premature twins or triplets and compared them to 120 premature singletons; they found a higher frequency of ROP in low BW twins and triplets, with no statistic difference. ${ }^{26}$

Baar et $\mathrm{al}^{26}$ did not find ROP greater than stage 1 in the 51-strong party of triplets evaluated for 10 years, but Kaufman et $\mathrm{al}^{10}$ suggested that triplets had a greater risk of ROP.

When this study noted the occurrence of any stage ROP in Group 1 (56 twins), 30 (53,6\%) had the disease, and in Group 2 (103 singletons), 36 (35\%) had any stage ROP. Chi-square test showed that Group 1 had a higher frequency of any stage of ROP than Group 2, which was statistically significant. However, the study did not include logistic regression to analyze behavior of gemelarity as a risk factor for ROP under influence of the other studied risk factors.

These data support the higher frequency of any stage of ROP among multiples (Group 1) but not regarding threshold ROP. In this study, three patients (5.3\%) from Group 1 (multiples) and nine patients (8.7\%) in Group 2 (singletons) reached threshold ROP needing diode laser treatment (Fisher's exact test $P>0.05$ ). Although babies born from multiple gestations appear to have the same GA, the siblings can have different intrauterine maturity levels by birth. In addition, they can achieve different clinical course during the postnatal period and this can affect the occurrences of ROP, and of severe ROP needing treatment among these patients.

As studies concerning gemelarity among very low BW preterm infants have the limitation of the small number of included patients, it is necessary to have more studies in this subject in order to determine if and how gemelarity plays a role in the occurrence of ROP.

\section{Disclosure}

The authors report no conflicts of interest in this work.

\section{References}

1. Weakley DR Jr, Spencer R. Current concepts in retinopathy of prematurity. Early Hum Dev. 1992;30(2):121-138.

2. Palmer EA. The continuing threat of retinopathy of prematurity. Am J Ophthalmol. 1996;122(3):420-423.

3. Fielder AR, Shaw DE, Robinson J, et al. Natural history of retinopathy of prematurity: a prospective study. Eye (Lond). 1992;6(Pt 3):233-242.

4. Arrøe M, Peitersen B. Retinopathy of prematurity in a Danish neonatal intensive care unit, 1985-1991. Acta Ophthalmol Suppl. 1993;210: $37-40$.

5. Phelps DL. Retinopathy of prematurity: an estimate of vision loss in the United States-1979. Pediatrics. 1981;67(6):924-926.

6. White GL Jr, Trainor SF, Kivlin JD, et al. Identification and treatment of retinopathy of prematurity: an update and review. South Med J. 1991;84(4):475-478.

7. Barr S, Poggi S, Keszler M. Triplet morbidity and mortality in a large case series. J Perinatol. 2003;23(5):368-371.

8. Friling R, Rosen SD, Monos T, et al. Retinopathy of prematurity in multiple-gestation, very low birth weight infants. J Pediatr Ophthalmol Strabismus. 1997;34(2):96-100.

9. Blumenfeld LC, Siatkowski RM, Johnson RA, et al. Retinopathy of prematurity in multiple-gestation pregnancies. Am J Ophthalmol. 1998; 125(2):197-203.

10. Kaufman GE, Malone FD, Harvey-Wilkes KB, et al. Neonatal morbidity and mortality associated with triplet pregnancy. Obstet Gynecol. 1998;91(3):342-348.

11. Watts $\mathrm{P}$, Adams GG. In vitro fertilisation and stage 3 retinopathy of prematurity. Eye (Lond). 2000;14(Pt 3A):330-333.

12. Nahoum JC. Gemelidade [Twins]. In: Rezende J, editor. Obstetrícia [Obstetrics]. 7th ed. Rio de Janeiro, Brazil: Guanabara Koogan; 1995:817. Portuguese.

13. Zin A, Florêncio T, Fortes Filho JB, et al. Proposta de diretrizes brasileiras do exame e tratamento de retinopatia da prematuridade (ROP) [Brazilian guidelines proposal for screening and treatment of retinopathy of prematurity (ROP)]. Arq Bras Oftalmol. 2007;70(5):875-883. Portuguese.

14. Cryotherapy for Retinopathy of Prematurity Cooperative Group [no authors listed]. Multicenter trial of cryotherapy for retinopathy of prematurity. Preliminary results. Arch Ophthalmol. 1988;106(4): 471-479.

15. Banach MJ, Ferrone PJ, Trese MT. A comparison of dense versus less dense diode laser photocoagulation patterns for threshold retinopathy of prematurity. Ophthalmology. 2000;107(2):324-327, discussion 328. 
16. The Committee for the Classification of Retinopathy of Prematurity [no authors listed]. An international classification of retinopathy of prematurity. Arch Ophthalmol. 1984;102(8):1130-1134.

17. Nyboe AA, Goossens V, Bhattacharya S, et al. Assisted reproductive technology and intrauterine inseminations in Europe, 2005: results generated from European registers by ESHRE: ESHRE. The European IVF Monitoring Programme (EIM), for the European Society of Human Reproduction and Embryology (ESHRE). Hum Reprod. 2009; 24(6):1267-1287. [Epub ahead of print.]

18. Fortes Filho JB, Eckert GU, Tartarella MB, et al. Prevenção da retinopatia da prematuridade [Prevention of retinopathy of prematurity]. Arq Bras Oftalmol. 2011;74(3):217-221. Portuguese.

19. McGregor ML, Bremer DL, Cole C, et al. Retinopathy of prematurity outcome in infants with prethreshold retinopathy of prematurity and oxygen saturation $>94 \%$ in room air: the high oxygen percentage in retinopathy of prematurity study. Pediatrics. 2002;110(3):540-544.

20. Gleissner MW, Spantzel T, Bücker-Nott HJ, et al. Risikofaktoren für die Entstehung einer Frühgeborenenretinopathie bei einem Gestationsalter von 32 bis 36 Schwangerschaftswochen [Risk factors of retinopathy of prematurity in infants 32 to 36 weeks gestational age]. Z Geburtshilfe Neonatol. 2003;207(1):24-28. German.
21. Fellows RR, McGregor ML, Bremer DL, et al. Retinopathy of prematurity in discordant twins. J Pediatr Ophthalmol Strabismus. 1995;32(2):86-88.

22. McKibbin M, Booth AP, Dabbs TR. In vitro fertilisation and stage 3 retinopathy of prematurity. Eye (Lond). 2001;15(Pt 3):363-364.

23. McKibbin M, Dabbs TR. Assisted conception and retinopathy of prematurity. Eye (Lond). 1996;10(Pt 4):476-478.

24. Bassler D, Stoll BJ, Schmidt B, et al. Using a count of neonatal morbidities to predict poor outcome in extremely low birth weight infants: added role of neonatal infection. Pediatrics. 2009;123(1):313-318.

25. Robinson R, O'Keefe M. Follow-up study on premature infants with and without retinopathy of prematurity. Br J Ophthalmol. 1993;77(2): 91-94.

26. Tomazzoli L, Renzi G, Mansoldo C. Ophthalmologic follow-up of premature twins and triplets. Eur J Ophthalmol. 2003;13(5):439-444.
Clinical Ophthalmology

\section{Publish your work in this journal}

Clinical Ophthalmology is an international, peer-reviewed journal covering all subspecialties within ophthalmology. Key topics include: Optometry; Visual science; Pharmacology and drug therapy in eye diseases; Basic Sciences; Primary and Secondary eye care; Patient Safety and Quality of Care Improvements. This journal is indexed on

Submit your manuscript here: http://www.dovepress.com/clinical-ophthalmology-journal

\section{Dovepress}

PubMed Central and CAS, and is the official journal of The Society of Clinical Ophthalmology (SCO). The manuscript management system is completely online and includes a very quick and fair peer-review system, which is all easy to use. Visit http://www.dovepress.com/ testimonials.php to read real quotes from published authors. 